\title{
A Pharmacokinetic Study of Native E.coli Asparaginase for Acute Lymphoblastic Leukemia Treated with ThaiPOG Protocol
}

\author{
Phumin Chaweephisal ${ }^{1}$, Trai Tharnpanich ${ }^{2}$, Aphinya Suroengrit ${ }^{1}$, Pattramon \\ Aungbamnet ${ }^{1}$, Panya Seksarn ${ }^{1}$, Darintr Sosothikul ${ }^{1}$, Supanun Lauhasurayotin ${ }^{1}$, \\ Kanhatai Chiengthong ${ }^{1}$, Hansamon Poparn ${ }^{1}$, Piti Techavichit ${ }^{1 *}$
}

\begin{abstract}
Background: Asparaginase is one of the essential chemotherapies used to treat acute lymphoblastic leukemia (ALL). Asparaginase antibody production may cause a subtherapeutic level and result in an inferior outcome. The aim of this study was to prove the efficacy of current native E.coli asparaginase-based protocol. Moreover, does subtherapeutic result appeared in small group of the trial?. Methods: A prospective study of asparaginase activity among patients who received native E.coli asparaginase $10,000 \mathrm{IU} / \mathrm{m}^{2}$ intramuscularly according to The Thai Pediatric Oncology Group (ThaiPOG) protocol was done. The plasma asparaginase activity was measured by the coupled enzymatic reaction. Pharmacokinetic data including peak activity $\left(\mathrm{C}_{\max }\right)$, time to maximum concentration $\left(\mathrm{T}_{\max }\right)$, area under the curve $\left(\mathrm{AUC}_{0-48 \mathrm{~h}}\right)$ being elucidated. Results: Eight patients (five males and three females), median age 9.5 years, were enrolled. The median asparaginase activity of seven cases who were eligible for calculation reached Tmax within 24 hours (range 6-48 hours) with mean $\pm \mathrm{SD}$ of $\mathrm{C}_{\max } 3.60 \pm 0.34$ (range 3.02-4.11) IU/ml. Mean $\pm \mathrm{SD}$ of $\mathrm{AUC}_{0-48 \mathrm{~h}}$ is $143.23 \pm 36.94 \mathrm{IU} . \mathrm{h} / \mathrm{mL}$ (range $71.07-180.12 \mathrm{IU} . \mathrm{h} / \mathrm{mL}$ ). The post-48-hour activity showed a mean $\pm \mathrm{SD}$ of $3.19 \pm 0.24$ $\mathrm{IU} / \mathrm{ml}$ (range 2.77-3.51 IU/ml) which implied an adequacy of activity over 48 hours and proper for the 12-day period. One relapsed ALL patient showed an extremely low AUC of asparaginase activity which coincided with urticaria after asparaginase injection. Subsequently, the asparaginase antibody was demonstrated in this patient. Conclusion: Native E. coli asparaginase-based protocol provides a compelling pharmacokinetic effect. Asparaginase activity and/ or antibody testing is recommended for all cases especially in a relapsed patient, history of high accumulative dose of asparaginase or suspected allergic reaction. Patients with low asparaginase activity or allergy may benefit from switching to an alternative form of asparaginase to maintain treatment efficacy.
\end{abstract}

Keywords: Native- asparaginase- silent inactivation- allergy- pharmacokinetic

Asian Pac J Cancer Prev, 22 (10), 3309-3315

\section{Introduction}

Acute lymphoblastic leukemia (ALL) is the most common malignancy in childhood accounting for 22.2 per million person-years between the ages of 0-19 years in Thailand with an age-standardized incidence rate ranging from 1.08 to 2.12 per 100,000 person-years worldwide (Bidwell et al., 2019; Katz et al., 2015). Many factors affect the survival rate including age, induction remission status, cytogenetics, and central nervous system involvement. Recent data have shown that the level of certain chemotherapy agents may affect the survival rate especially asparaginase which is the backbone chemotherapy in many phases of treatment
(Wetzler et al., 2007; Riccardi et al., 1981). A study in adult ALL age 17 to 71 revealed that patients who could not maintain plasma asparaginase activity greater than 0.03 $\mathrm{IU} / \mathrm{ml}$ at post-14 days had inferior overall survival (OS) $(\mathrm{p}=0.002 ; \mathrm{HR}=2.37 ; 95 \% \mathrm{CI}=1.38-4.09)$ and reduced disease-free survival (DFS) $(\mathrm{p}=0.012 ; \mathrm{HR}=2.21 ; 95 \%$ $\mathrm{CI}=1.19-4.13$ ) (Wetzler et al., 2007). A study of monkeys and humans demonstrated that following intravenous asparaginase administration, an plasma asparaginase activity of more than $0.1 \mathrm{IU} / \mathrm{ml}$ can deplete the central nervous system (CNS) asparagine in both species and may cause effectiveness (Riccardi et al., 1981). The descriptive study of 262 patients received native E.coli asparaginase from two different manufacturer Aginasa ${ }^{\circledR}$ 
and Leuginase ${ }^{\circledR}$ showed post-48 hour activity (above 0.1 $\mathrm{IU} / \mathrm{ml}$ ) achieved in $81 \%$ and $3 \%$ of patients respectively. The six patients died, five with active disease in the only group of Leuginase ${ }^{\mathbb{R}}$. It might be a good demonstration of correlation of activity and outcome (Cecconello et al., 2018).

The main mechanism of asparaginase works to metabolize L-asparagine to L-aspartic acid. The process causes depletion of asparagine which is an essential amino acid for the leukemic cells (Ho et al., 1970). Asparagine deficiency ceases cell differentiation and induces cell death. Nowadays, three or more forms of asparaginase are available, native E.coli asparaginase, pegylated asparaginase, and Erwinia asparaginase (Metayer et al.,2019). Native E.coli asparaginase is the prototype first introduced in ALL treatment in 1968 and has subsequently shown to increase remission rate from 86 to $93 \%$ when combined with other treatments (Ortega et al., 1977). However, pegylated asparaginase has currently replaced native E.coli and is used as the first-line drug because of its more rapid clearance of lymphoblasts cells in bone marrow, prolonged plasma asparaginase activity, and lower hypersensitivity events (Ortega et al., 1977; Avramis et al., 2002). If native E.coli pegylated asparaginase allergy develops, Erwinia asparaginase is indicated because of its immunological distinction and lack of cross reactivity (Egler et al., 2016).

This study was based on the standard chemotherapy guidelines of Thailand under the ThaiPOG 2018 protocol (The Thai Pediatric Oncology Group, 2018). The classification risk of ALL patients was stratified as standard, high, and very high risk and correlated with the standard, high, and very high-risk ThaiPOG protocols. The guidelines were adapted from the Children's Oncology Group (COG) guideline (COG AALL0932(Children's Oncology Group, 2015), AALL1131(Children's Oncology Group, 2015)). For ThaiPOG 2018, asparaginase was administrated intramuscularly exclusively in the form of native E.coli asparaginase. All risk groups completed up to five sessions of asparaginase from induction to delayed intensification (DI) phase. Each session is comprised of 6 doses of $10,000 \mathrm{IU} / \mathrm{m}^{2}$ given every other day and completed within 12 days.

One pharmacokinetics study of native E.coli asparaginase $\left(6,000 \mathrm{IU} / \mathrm{m}^{2}\right.$ intramuscular administration in the induction phase and DI phases 1 and 2) revealed that peak activity in one patient reached $2 \mathrm{IU} / \mathrm{ml}$ at 4 hours after injection (Avramis et al., 2002). The sample of 59 patients had a mean elimination half-life of 1.8 days during the induction phase and 1.5 days in DI 1-2. Adequate plasma asparaginase activity in DI 1-2 determined by activity above $0.1 \mathrm{IU} / \mathrm{ml}$ was found in $19-22 \%$ of cases after 21 days of administration (Avramis et al., 2002).

Another pharmacokinetics study of native E.coli asparaginase, mostly $10,000 \mathrm{IU} / \mathrm{m}^{2}$ intramuscularly in some cancer patients, documented that plasma activity could be detected initially within the first hour (Ho et al., 1981). The peak activity occurred between 14 to 24 hours at a level of $1.12 \pm 0.14 \mathrm{IU} / \mathrm{ml}$. The half-life was 41.7 \pm 4.3 hours (range $34-49$ hours). The durable activity lasted above $0.1 \mathrm{IU} / \mathrm{ml}$ for more than 8 days. Volume distribution (Vd) was $245 \pm 28 \mathrm{ml} / \mathrm{kg}$ and area under the curve (AUC) was $18-22 \mathrm{IU} / \mathrm{ml}$ per hr. This study identified one case with a very low peak activity of 0.04 $\mathrm{IU} / \mathrm{ml}$. The presumptive explanation might be from obesity which traps the drug subcutaneously and impacts antibody production or other parts of the proteolytic degradation process (Riccardi et al., 1981; Walenciak et al., 2019).

Asparaginase is not normally found in humans, therefore, it is possible to induce the production of autoimmunity against the drug. With the antibody production, some patients may have the clinical appearance as urticaria or anaphylaxis from hypersensitivity type I mechanism. However, other patients do not have any clinical manifestations which is called silent inactivation. The major problem with both types of response groups is that lowering the plasma asparaginase activity can reduce effectiveness. The antibody was found in $28 \%$ (16 of 57) of native E.coli asparaginase and 12\% (7 of 56) of pegylated asparaginase. Both types found cross-reactivity between the groups. Erwinia asparaginase which is produced from fungus of a species of E.chrysanthemi also has hyperreactivity, but does not cross-react with other types (Wang et al., 2003). The antibody-positive status is an indication to shift the drug to another formula to maintain the efficacy of leukemia treatment (Dinndorf et al., 2007). The aim of this study was to prove the efficacy of current native E.coli asparaginase-based protocol. Moreover, does subtherapeutic result appeared in small group of the trial?

\section{Materials and Methods}

\section{Study objectives}

This is the prospective pharmacokinetic study of native E.coli asparaginase at $10,000 \mathrm{IU} / \mathrm{m}^{2}$ administration intramuscularly during the induction and DI phase following the ThaiPOG 2018 protocol for childhood ALL. The results were documented by measuring plasma asparaginase activity and calculating pharmacokinetic parameter values. The appropriate activity is determined by a level above $0.1 \mathrm{IU} / \mathrm{ml}$ throughout the treatment period which indicates drug efficacy. This method emphasizes drug monitoring, which is now routinely practiced in some countries.. The study may also support the effectiveness of the native E.coli asparaginase formula used in the ThaiPOG2018 protocol.

\section{Ethics and inclusion/exclusion criteria}

The study was approved by the Institutional Ethics Committee, King Chulalongkorn Memorial Hospital (IRB number: 258/63). The inclusion criteria were all patients who received ALL protocol between the age of 1 to 18 years, limited to 8 cases. Patients were still under induction (phase I) or DI (phase IV) period at King Chulalongkorn Memorial Hospital (KCMH), Bangkok, Thailand from September 2020 through June 2021. The exclusion criteria included patients less than 1 year, body weight below 10 kilograms or $3^{\text {rd }}$ percentile, and parent refusal to participate. Eight eligible patients were recruited. Native E.coli asparaginase, under the tradename of LEUNASE ${ }^{\circledR}$ manufactured by Kyowa Kirin Corporation, Japan, was administrated intramuscularly at a dose of $10,000 \mathrm{IU} / \mathrm{m}^{2}$ 
6 doses given every other day over a period of 12 days

\section{Sample collection and quantification methods}

Blood samples were drawn via a central venous catheter a total of 9 times: baseline ( 0 ) before injection, and then at $0.25,0.5,1.0,2.0,4.0,6.0,24$, and 48 hours after the first dose, respectively. The post-first dose sample was taken to ensure the activity level would not be affected by previous injections. However, the monitoring was limited to 48 hours after second dose administration. Each sample was filled in a heparin tube and centrifuged at 3,000 rounds per second for 15 minutes to separate the plasma. The products were stored at -80 degrees Celsius. All steps were processed within 1 hour after collection. Time collection was recorded. The plasma asparaginase activity were measured by the coupled enzymatic reaction using Asparaginase Activity Assay Kit (Raybiotech ${ }^{\circledR}$, United States) product. The reaction was determined by using the Varioskan Flash spectral scanning multimode reader at $570 \mathrm{~nm}$ (Thermo Scientific ${ }^{\circledR}$, Thailand). The day-to-day variation was controlled by process ELISA at one point-in-time after all samples had been collected.

If detected low asparaginase activity, the plasma asparaginase-specific antibody testing would be performed on post-48 hours of the last of all asparaginase doses. The

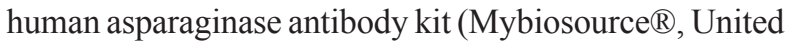
states), the coupled enzymatic reaction technique, was used for antibody quantitative measurement.

\section{Statistical analysis}

The baseline activity ( 0 hour) was utilized for calibration. The pharmacokinetic parameters were calculated by non-compartmental analysis (NCA) model and $\mathrm{PK}$ software program (PCModfit ${ }^{\circledR}$ version 6.9, UK). The area under the curve (AUC) was demonstrated by linear trapezoidal rule $\left(\mathrm{AUC}_{0 \text {-inf }}\right)$ reflecting data from 0 to 48 hours after injection.

\section{Results}

Demographic data are shown in Table 1. Eight patients were recruited, five males and three females. The median age was 9.5 years (range 1-12 years-old). Seven patients who were newly diagnosed received the ThaiPOG ALL protocol which divided the patients into 3 risk categories: standard, high, and very high risk. One patient who was diagnosed with late combined medullary and CNS relapsed disease received the high-risk chemotherapy protocol due to the decision to proceed without hematopoietic stem cell transplantation. All patients followed the ThaiPOG 2018 guidelines requiring native E.coli asparaginase 10,000 IU/m $\mathrm{m}^{2} 6$ doses given intramuscularly every other day over a period of 12 days and with regular follow up for complications more than six months. All complications were recorded. The concurrent combination chemotherapies are vincristine, doxorubicin, intrathecal methotrexate, and systemic steroid, all identically. Antimicrobial agents and supportive drugs were not considered in our study.

The asparaginase activities of seven cases were measured at all 9 time points and displayed in Figure 1.
A pharmacokinetic Study of Native E.coli Asparaginase

The pharmacokinetic parameters were shown in Table 2 (excluding one case (case $\mathrm{H}$ ) with extremely low

Table 1. Demographic and Clinical Data of Patients $(\mathrm{n}=8)$

\begin{tabular}{|c|c|}
\hline Data & $\mathrm{N}$ (percent) \\
\hline \multicolumn{2}{|l|}{ Diagnosis } \\
\hline ALL & $7(87.5 \%)$ \\
\hline T-lymphoblastic lymphoma & $1(12.5 \%)$ \\
\hline \multicolumn{2}{|l|}{ Phase of study } \\
\hline Induction & $3(37.5 \%)$ \\
\hline Delay intensification & $5(62.5 \%)$ \\
\hline \multicolumn{2}{|l|}{ Age (years) } \\
\hline $0-3$ & $2(25 \%)$ \\
\hline $4-10$ & $2(25 \%)$ \\
\hline $10-13$ & $4(50 \%)$ \\
\hline$>14$ & 0 \\
\hline \multicolumn{2}{|l|}{ Initial WBC count (cell/ $\left./ \mathrm{mm}^{3}\right)$} \\
\hline$<10,000$ & $6(75 \%)$ \\
\hline $10,000-50,000$ & 0 \\
\hline$>50,000$ & $2(25 \%)$ \\
\hline \multicolumn{2}{|l|}{ CNS involvement ${ }^{*}$} \\
\hline Yes & $2(25 \%)$ \\
\hline No & $6(75 \%)$ \\
\hline \multicolumn{2}{|l|}{ Cytogenetics } \\
\hline Normal & $5(62.5 \%)$ \\
\hline Abnormal $^{ \pm}$ & $2(25 \%)$ \\
\hline No data & $1(12.5 \%)$ \\
\hline \multicolumn{2}{|c|}{ Remission after 28 days of induction } \\
\hline CR1 & $7(87.5 \%)$ \\
\hline $\mathrm{CR} 2$ & $1(12.5 \%)$ \\
\hline \multicolumn{2}{|c|}{ MRD status after 28 days of induction } \\
\hline Positive & 0 \\
\hline Negative & $8(100 \%)$ \\
\hline
\end{tabular}

Chemotherapy ALL protocol (corresponding to risk stratification)

Standard

High $^{\pi}$

Very high

$1(12.5 \%)$

Relapse after 6 months enrollment

0

Complication (exclude infection)

Asparaginase allergy (urticaria) 1/8

Methotrexate allergy (maculopapular rash) $\quad 1 / 8$

Bactrim allergy (anaphylaxis) $\quad 1 / 8$

Fracture tibia

$1 / 8$

Abbreviation: ALL, acute lymphoblastic leukemia; CNS, central nervous system; CR1, first complete remission; CR2, second complete remission; MRD, minimal residual disease; $\mathrm{WBC}$, white blood cells; ${ }^{*} \mathrm{CNS}$ involvement defined by CNS $\mathrm{WBC} \geq 3$ cells and positive cytopathology; ${ }^{ \pm}$Cytogenetics abnormality including 46, XY, der(6), $\mathrm{t}(6 ; ?)(\mathrm{q} 21 ; ?), \operatorname{add}(9)(\mathrm{p} 21), \operatorname{del}(9)(\mathrm{p} 13)$ and 46,XX, add(15)(p11.2); ${ }^{\pi}$ One patient who had late combined medullary/CNS relapsed disease received high-risk chemotherapy protocol due to the decision to proceed without hematopoietic stem cell transplantation. Another patient who had a diagnosis of T-lymphoblastic lymphoma was treated with the high-risk protocol. 
Table 2. Pharmacokinetic Profiles of Seven Cases who are Eligible for Calculation after Native E.coli Asparaginase $10,000 \mathrm{IU} / \mathrm{m}^{2}$ Intramuscular Injection

\begin{tabular}{lcccccccccccccc}
\hline $\begin{array}{l}\text { Case } \\
\text { profile }\end{array}$ & A & B & C & D & E & F & G & Min. & Max. & Mean & GMean & Median & SD & CV \\
\hline $\begin{array}{l}\text { AUC time } \\
\text { range }\end{array}$ & 0 to 48 & 0 to 48 & 0 to 24 & 0 to 48 & 0 to 48 & 0 to 48 & 0 to 48 & - & - & - & - & - & - & - \\
$\mathrm{T}_{\max }$ & 24 & 24 & 24 & 24 & 24 & 24 & 6 & 6 & 24 & - & - & 24 & - & - \\
$\mathrm{C}_{\max }$ & 3.47 & 3.85 & 3.53 & 3.51 & 4.11 & 3.02 & 3.71 & 3.02 & 4.11 & 3.6 & 3.58 & 3.53 & 0.34 & 9.54 \\
Log AUC & 137.14 & 173.93 & 71.07 & 143.29 & 180.12 & 131.47 & 165.59 & 71.07 & 180.12 & 143.23 & 137.99 & 143.29 & 36.94 & 25.8 \\
$\begin{array}{l}\text { Post-48-hr } \\
\text { activity }\end{array}$ & 3.22 & 3.51 & - & 3.3 & 3.18 & 2.77 & 3.18 & 2.77 & 3.51 & 3.19 & - & 3.2 & 0.24 & - \\
\hline
\end{tabular}

Abbreviation: AUC or Log AUC, area under the curve; $\mathrm{CV}$, coefficient of variation; $\mathrm{C}_{\max }$, maximum concentration; $\mathrm{SD}$, standard deviation; $\mathrm{T}_{\max }$, time-to-peak activity level; ${ }^{\pi}$ The pharmacokinetic graph was shown in Figure 1.

Table 3. Pharmacokinetic Profiles of Case $\mathrm{H}$ after Native E.coli Asparaginase 10,000 IU/m² Intramuscular Injection and Asparaginase-Specific Antibody Test

\begin{tabular}{lc}
\hline Case profile & Case $\mathrm{H}^{\pi}$ \\
\hline AUC time range & 0 to 48 \\
$\mathrm{~T}_{\max }(\mathrm{h})$ & 48 \\
$\mathrm{C}_{\max }(\mathrm{IU} / \mathrm{mL})$ & 1.06 \\
Log AUC 0 to 48 (IU.h/mL) & 22.84 \\
post-48-hour activity & 1.06 \\
Asparaginase-specific antibody $(\mathrm{ng} / \mathrm{ml})$ & Positive* \\
\hline
\end{tabular}

Abbreviation: AUC or Log AUC, area under the curve; $\mathrm{C}_{\max }$, maximum concentration; $\mathrm{T}_{\max }$, time-to-peak activity level; ${ }^{\pi}$ The pharmacokinetic graph was shown in Figure 2; *Asparaginase-specific antibody was $1.31(\mathrm{ng} / \mathrm{ml})$ (2.8 times of control). A value of more than 2.5 times of normal is considered positive. The mean level of another four volunteers (controlled cases) who did not have history of asparaginase administration was $0.48 \mathrm{ng} / \mathrm{ml}$.

values). The time-to-peak activity level $\left(\mathrm{T}_{\max }\right)$ appeared most often at 24 hours (range 6-48 hours). The mean maximum concentration $\left(\mathrm{C}_{\max }\right) \pm \mathrm{SD}$ was $3.60 \pm 0.34 \mathrm{IU} /$ $\mathrm{ml}$ (range 3.02-4.11 IU/ml), then decrease subsequently. Mean $\pm \mathrm{SD}$ of $\mathrm{AUC}_{0-48 \mathrm{~h}}$ was $143.23 \pm 36.94 \mathrm{IU} . \mathrm{h} / \mathrm{mL}$ (range $71.07-180.12 \mathrm{IU} . \mathrm{h} / \mathrm{mL}$ ). The post-48-hour activity mean \pm SD was $3.19 \pm 0.24 \mathrm{IU} / \mathrm{ml}$ (range 2.77-3.51 IU/ $\mathrm{ml}$ ) which implied an adequacy of activity over the 48 hours and the total 12 days period for all seven cases. We successfully showed the peak level of the drug, but failed to demonstrate the half-life because of the limitation of the 48-hour interval between each dose. The highest $\mathrm{AUC}_{0-48 \mathrm{~h}}$ exhibited was case E. It was presumed most potentially to have some side effect. However, there is no report any side effects of asparaginase including hypercoagulable state, coagulopathy, pancreatitis, and hyperbilirubinemia. Additional data are required to support a more definite correlation.

The extremely low pharmacokinetic values of another one case $(\mathrm{H})$ were shown in FIGURE 2 and Table 3. This patient had a medical history of combined medullary/CNS relapse status which coincided with clinical allergy as urticaria for the last two doses of native E.coli asparaginase on DI time. Insufficient data prevents an explanation of whether a lower AUC might be a factor for disease relapse. Further investigation of case $\mathrm{H}$ demonstrated an asparaginase-specific antibodypositive status (Table 3 ).

\section{Discussion}

Our study demonstrated that six doses of native E.coli asparaginase administrated intramuscularly at a dose of $10,000 \mathrm{IU} / \mathrm{m}^{2}$ elucidated sufficient asparaginase effectiveness with a post-48 hour activity level $>0.1 \mathrm{IU} /$ $\mathrm{ml}$ in all 7 cases We had assumed that the activity level

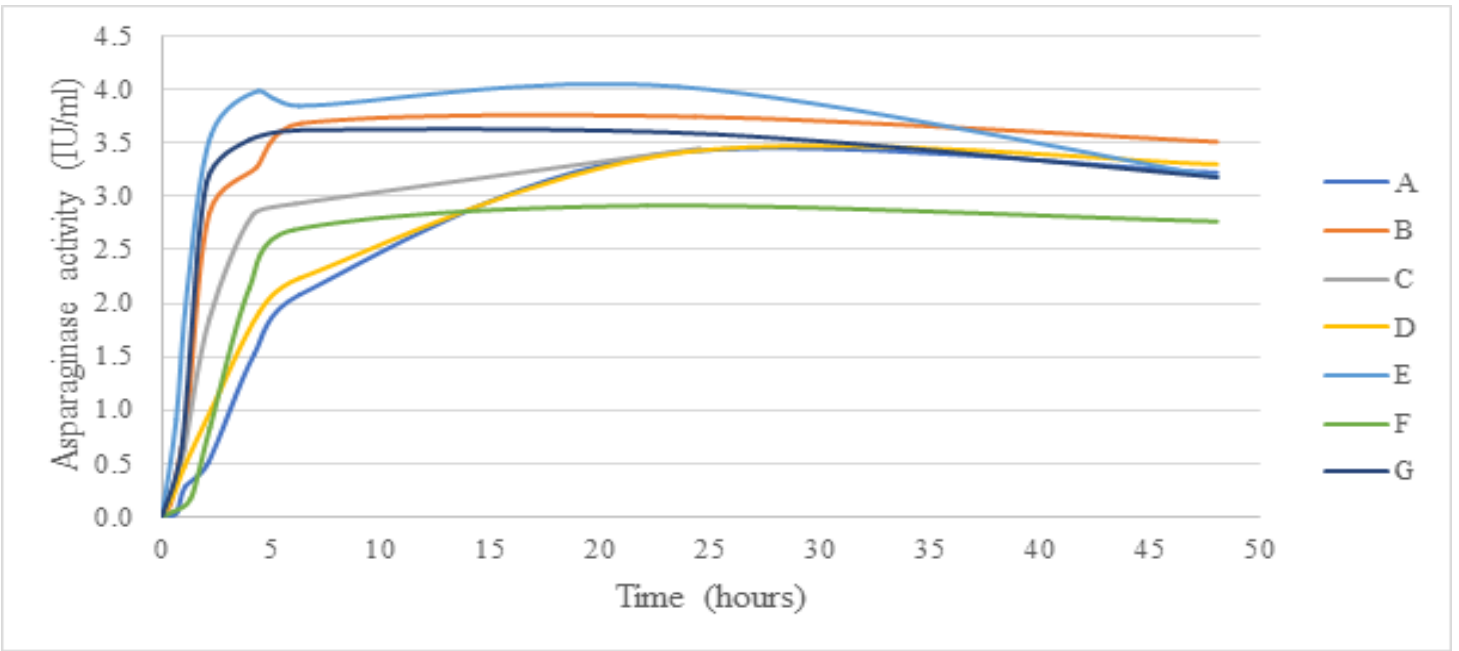

Figure 1. Asparaginase Activity of Seven Cases who are Eligible for Calculation at Selected Time Points after Native E.coli Asparaginase Intramuscular 10,000 IU/m² Injection. 


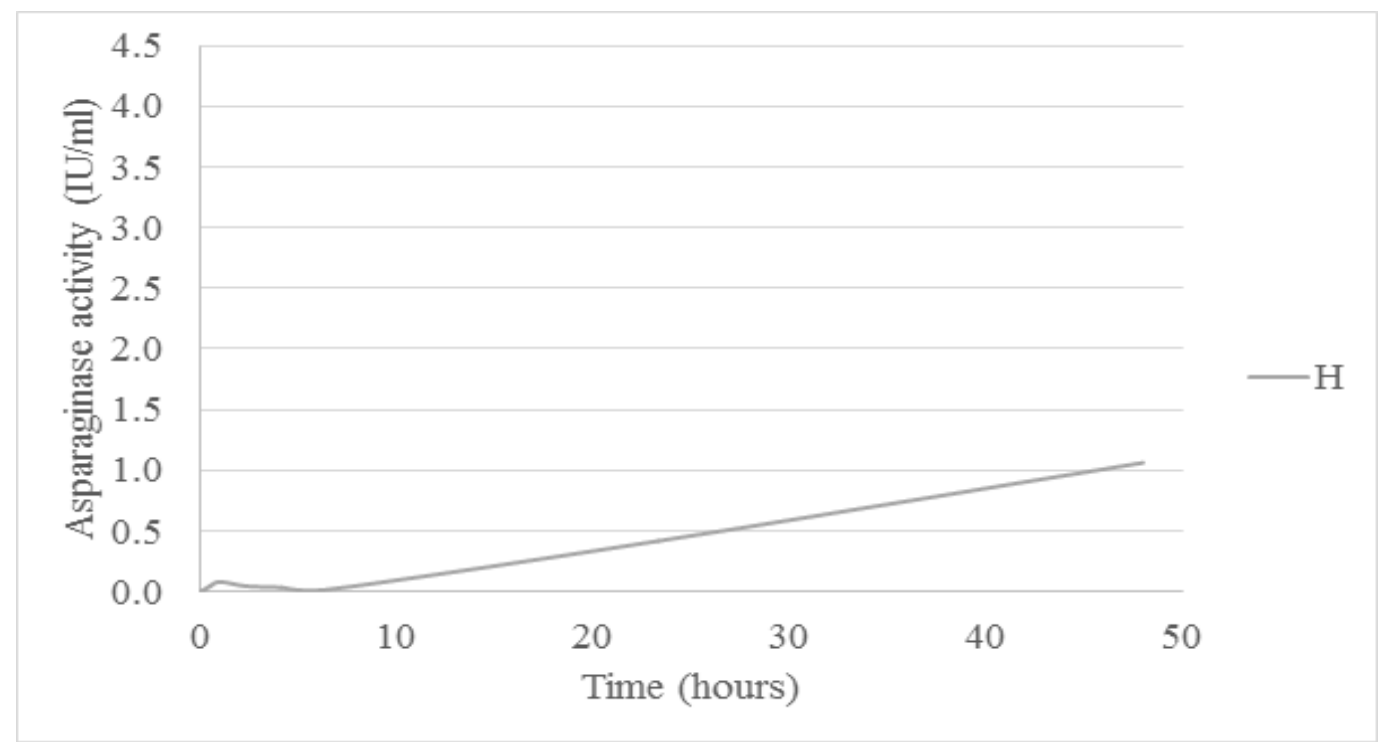

Figure 2. Asparaginase Activity of Another One Case at Selected Time Points after Native E.coli Asparaginase Intramuscular 10,000 IU/m² Injection.

might be above the cut-off throughout the given period at 12 days or greater. However, this study did not show evidence of a latency of asparaginase activity after 48 hours (or at 14 days or 21 days or end of induction) which was reported in previous literature at different time points. Due to a small study population, interpretation of our results should be restricted.

This pharmacokinetic study revealed an identical mean time to reach maximum concentration $\left(\mathrm{T}_{\max }\right)$ which presented at 24 hours (between 6-48 hours) as previous studies. However, the mean peak serum concentration $\left(\mathrm{C}_{\max }\right) \pm \mathrm{SD}$ was $3.60 \pm 0.34 \mathrm{IU} / \mathrm{ml}$ (range $3.02-4.11 \mathrm{IU} /$ $\mathrm{ml}$ ) which was 1.5-3.7 times greater than other reports (Riccardi et al., 1981; Avramis et al., 2002).

The AUC,which represents the total drug exposure across time, was calculated on therapeutic drug monitoring, the possibility of dose adjustment within the reference range apart from the activity level as same as carboplatin and busulfan. Furthermore, it was performed for the calculation of elimination factors. However, no $\mathrm{AUC}_{0-48 \mathrm{~h}}$ referable values were purposed for native E.coli asparaginase to adjust. Further studies are required.

We described one case of a relapsed patient who had a lower level of activity compared with the other 7 cases in our study. The highest activity was only 1.06 $\mathrm{IU} / \mathrm{ml}$. This case had also reported asparaginase clinical hyperreactivity as urticaria. The activity showed clinical correlation with a lower level than usual implying that antibody production might have contributed to this result. This patient was studied during the DI phase where it had been reported to develop antibodies more than during induction time (Avramis et al., 2002). The duration of activity above $0.1 \mathrm{IU} / \mathrm{ml}$ for this case is still unknown.

Native E.coli asparaginase offers few drug interactions. No reports of other combination chemotherapies as vincristine, doxorubicin, intrathecal methotrexate, or systemic corticosteroid will affect asparaginase activity, although asparaginase may affect certain drugs (Lexicomp Online Database [database on the Internet],
2021). Its molecular weight remains unchanged and no other metabolized products can be found after ex-vivo incubation. It is also not present in urine. The elimination mechanism still be unclear but thought to be driven by the reticuloendothelial system (Pinheiro and Boos, 2004; Brueck et al., 1989).

Many experts have documented the benefit of routinely measuring asparaginase activity in all cases receiving the ALL protocol as the standard of care, because silent inactivation may cause the drug to fall below the cut-off values without clinical notice (van der Sluis et al., 2016). Some of measurement protocols recommend only day 14 after the first dose. Asparaginase activity greater than $0.1 \mathrm{IU} / \mathrm{ml}$ indicates medical effectiveness. These recommendations were written for the native E.coli asparaginase three-time a week schedule where 72 hours post-dose activity occurs post-14 days of administration. The frequency of monitoring is recommended on the first post-14-day-period in every re-introduction of the drug. This recommendation is based on the native E.coli asparaginase-based protocol having a greater benefit to carry out monitoring due to the higher likelihood to induce the antibody production compared to other treatments. When clinical allergy developed or antibodies were detected correlation with subtherapeutic pharmacokinetics study/single-time point level, continuing the same formula caused the ALL treatment to become ineffective. Hence, it is inevitable to switch to a different form of asparaginase. If the clinical allergy is mild or doubtful or has multiple other suspected drugs to cause reaction during the same period, the asparaginase activity with or without the antibody check is also indicated (van der Sluis et al., 2016). Premedication with a steroid or anti-histamine can reduce the allergic symptoms, but no data supports an increase in asparaginase activity or effectiveness. The efficacy of pegylated asparaginase (sufficient activity) after a change from native E.coli asparaginase due to antibody production was $77-80 \%$ (Asselin, 2011). Switching to pegylated asparaginase should be carefully performed 
in this situation and clinicians may need to recheck the level during the next 7 and 14 days. The alternative is to switch to Erwinia asparaginase because there is no cross-reactivity especially in patients who have had severe clinical hypersensitivity.

In practice, only one or two time-point activity is recommended rather than full pharmacokinetic panel. The current available data of correlation between activity and outcome supported monitoring on post 48-hour for native form (Cecconello et al., 2018), post-14 day for pegylated form (Wetzler et al., 2007). No available study of correlation between outcome of Erwinia form and monitoring was varies between study ranged 24,48,72hour post administration (Salzer et al., 2013; Albertsen et al., 2001; van der Sluis et al., 2016). However, some recommended to monitor at post-48 hour (Brueck et al., 1989). For multiple injection, keeping level above 0.1 $\mathrm{IU} / \mathrm{ml}$ before the next dose is mandatory. Asparaginase antibodies are still not routinely recommended to monitor in practice (van der Sluis et al., 2016). Although, many studies performed antibody test at multiple various times after asparaginase administration (Dinndorf et al., 2007; Avramis et al., 2002).

The efficacy of pegylated asparaginase has been well established and is the primary reason for its use as the current first-line formula in ALL treatment protocol. In developing countries such as Thailand, however, the national protocol still requires only native E.coli asparaginase because pegylated asparaginase is rarely available and affordable. However, we are concerned since some patients may gain greater benefit if they receive pegylated asparaginase, especially cases involving relapsed patients or those at high risk for relapse or patients who have the potential to develop antibody (genetics polymorphism risks).

Native E.coli asparaginase administrated intramuscularly at a dose of $10,000 \mathrm{IU} / \mathrm{m}^{2} 6$ doses every other day over a period of 12 days provides a compelling pharmacokinetic effect compared to previous studies. Post-48-hour activity proved medical effectiveness to nearly entire cases. However, only one case developed asparaginase-specific antibody result in the extremely low plasma asparaginase activity. This special condition should have more concern. The asparaginase activity and/ or antibody testing is recommended for all cases especially in a relapsed patients, history of high accumulative dose of asparaginase or suspected allergic reaction to the asparaginase. The low asparaginase activity may notice from clinical hypersensitivity development, direct pharmacokinetic-proved low activity, or asparaginase antibody positive status. In this setting, switching to an alternative form of asparaginase may benefit to maintain leukemia treatment efficacy.

\section{Author Contribution Statement}

PC, TT, and PT designed and reviewed the results. AS and PA performed the laboratory studies. SL, HP, $\mathrm{KC}$, DS and PS involved in patients' care and collected the patient's data. PC and PT wrote and revised the manuscript. All authors read and approved the final version of the manuscript.

\section{Acknowledgments}

This work was supported by the Ratchadapiseksompotch Fund, Faculty of Medicine, Chulalongkorn University, under Grant number RA64/015. This study was approved from the institute ethic committee No.258/63. The institutional review board chief committee is Emeritus Professor Tada Sueblinvong, MD.

\section{Statement conflict of Interest}

The authors disclose no potential conflicts of interest.

\section{References}

Albertsen BK, Schroder H, Jakobsen P, et al (2001). Monitoring of Erwinia asparaginase therapy in childhood ALL in the Nordic countries. Br J Clin Pharmacol, 52, 433-7.

Asselin BL (2011). L-asparaginase for treatment of childhood acute lymphoblastic leukemia: what have we learned? Pediatr Blood Cancer, 57, 357-8.

Avramis VI, Sencer S, Periclou AP, et al (2002). A randomized comparison of native Escherichia coli asparaginase and polyethylene glycol conjugated asparaginase for treatment of children with newly diagnosed standard-risk acute lymphoblastic leukemia: a Children's Cancer Group study. Blood, 99,1986-94.

Avramis VA, Sencer S, Periclou AP, et al (2002). A randomized comparison of native Escherichia coli asparaginase and polyethylene glycol conjugated asparaginase for treatment of children with newly diagnosed standard-risk acute lymphoblastic leukemia: A Children's Cancer Group study. Blood, 99.

Bidwell SS, Peterson CC, Demanelis K, et al ( 2019). Childhood cancer incidence and survival in Thailand: A comprehensive population-based registry analysis, 1990-2011. Pediatr Blood Cancer, 66, e27428.

Brueck M, Koerholz D, Nuernberger W, et al (1989). Elimination of 1-asparaginase in children treated for acute lymphoblastic leukemia. Dev Pharmacol Ther, 12, 200-4.

Cecconello DK, Werlang ICR, AlegrettiAP, et al (2018). 'Monitoring asparaginase activity in middle-income countries. Lancet Oncol, 19, 1149-50.

Children's Oncology Group (2015a). 'AALL0932: Treatment of Patients with Newly Diagnosed Standard Risk B-Lymphoblastic Leukemia or Localized B-lineage Lymphoblastic Lymphoma'. https://childrensoncologygroup. org/aall0932.

Children's Oncology Group (2015b). 'AALL1131: A Phase III Randomized Trial for Newly Diagnosed High Risk B-precursor Acute Lymphoblastic Leukemia (ALL) Including a Stratum Evaluating Dasatinib in Patients with Ph-like Tyrosine Kinase Inhibitor (TKI) Sensitive Mutations'. https://childrensoncologygroup.org/AALL1131.

Dinndorf PA, Gootenberg J, Cohen MH, Keegan P, Pazdur R (2007). FDA drug approval summary: pegaspargase (oncaspar) for the first-line treatment of children with acute lymphoblastic leukemia (ALL). Oncologist, 12, 991-8.

Egler RA, Ahuja SP, Matloub Y (2016). L-asparaginase in the treatment of patients with acute lymphoblastic leukemia. $J$ Pharmacol Pharmacother, 7, 62-71.

Ho DH, Whitecar JP, Luce JK, Frei E (1970). L-asparagine requirement and the effect of $\mathrm{L}$-asparaginase on the normal and leukemic human bone marrow. Cancer Res, 30, 466-72. 
Ho DH, Yap HY, Brown N, et al (1981). Clinical pharmacology of intramuscularly administered L-asparaginase. J Clin Pharmacol, 21, 72-8.

Katz AJ, Chia VM, Schoonen WM, Kelsh MA (2015). Acute lymphoblastic leukemia: an assessment of international incidence, survival, and disease burden. Cancer Causes Control, 26, 1627-42.

Lexicomp Online Database [database on the Internet] (2021) 'Asparaginase (E. coli)'. https://www.uptodate.com/druginteractions/?source=responsive_home\#di-analyze.

Metayer LE, Brown RD, Carlebur S, Burke GAA, Brown GC (2019). Mechanisms of cell death induced by arginase and asparaginase in precursor B-cell lymphoblasts. Apoptosis, 24, 145-56.

Ortega JA, Nesbit ME, J Donaldson MH, et al (1977). 'L-Asparaginase, vincristine, and prednisone for induction of first remission in acute lymphocytic leukemia. Cancer Res, 37, 535-40.

Pinheiro JP, Boos J (2004). The best way to use asparaginase in childhood acute lymphatic leukaemia--still to be defined?'. Br J Haematol, 125, 117-27.

Riccardi R, Holcenberg JS, Glaubiger DL, Wood JH, Poplack DG (1981). L-asparaginase pharmacokinetics and asparagine levels in cerebrospinal fluid of rhesus monkeys and humans. Cancer Res, 41, 4554-8.

Salzer WL, Asselin B, Supko JG, et al (2013). Erwinia asparaginase achieves therapeutic activity after pegaspargase allergy: a report from the Children's Oncology Group'. Blood, 122, 507-14.

The Thai Pediatric Oncology Group (2018). National protocol for the treatment of childhood cancers 2018 (bangkok).

Van der Sluis IM, Vrooman LM, Pieters R, et al (2016). Consensus expert recommendations for identification and management of asparaginase hypersensitivity and silent inactivation. Haematologica, 101, 279-85.

Walenciak J, Wyka K, Janczar S, Mlynarski W, ZalewskaSzewczyk B (2019). Dynamic changes in specific anti-L-asparaginase antibodies generation during acute lymphoblastic leukemia treatment. Pharmacol Rep, 71, 311-8.

Wang B, Relling MV, Storm MC, et al (2003). Evaluation of immunologic crossreaction of antiasparaginase antibodies in acute lymphoblastic leukemia (ALL) and lymphoma patients. Leukemia, 17, 1583-8.

Wetzler M, Sanford BL, Kurtzberg J, et al (2007). Effective asparagine depletion with pegylated asparaginase results in improved outcomes in adult acute lymphoblastic leukemia: Cancer and Leukemia Group B Study 9511. Blood, 109, 4164-7.

This work is licensed under a Creative Commons AttributionNon Commercial 4.0 International License. 